\title{
Quantitative Approach to Glucocorticosteroids Analysis in Human Urine using LC-MS/MS
}

\author{
Renata F. Soares, Amanda L. D. de Araújo, Juliana de L. Castro, Luis Nelson L. F. Gomes, \\ Henrique M. G. Pereira* and Francisco R. de Aquino Neto
}

Instituto de Química, Universidade Federal do Rio de Janeiro, 21949-900 Rio de Janeiro-RJ, Brazil

\begin{abstract}
Glicocorticosteroides estão incluídos na lista de substâncias proibidas da Agência Mundial Antidoping como analitos que dispensam quantificação. Entretanto, abordagens semiquantitativas são necessárias antes de relatar um resultado analítico adverso para essa classe de substâncias. Cromatografia líquida acoplada à espectrometria de massa (LC-MS) tem sido empregada com excelente seletividade e especificidade na análise de xenobiontes em misturas complexas. Foram analisadas amostras contendo glicocorticosteroides exógenos, a partir de diferentes vias de administração, utilizando o método proposto. Amostras geradas após administração sistêmica (via oral) apresentaram níveis de prednisolona ou prednisona superiores a $30 \mathrm{ng} \mathrm{mL}^{-1}$, limite mínimo de desempenho requerido usado como parâmetro de diagnóstico. Por outro lado, vias não-sistêmicas parecem não apresentar biodisponibilidade para gerar um caso adverso em análises de controle de dopagem. Considerando o número reduzido de estudos similares na literatura, mais estudos de excreção podem ser realizados usando o método relatado com o objetivo de fornecer mais informações sobre o perfil de excreção de glicocorticosteroides administrados por vias sistêmicas e não sistêmicas.
\end{abstract}

Glucocorticosteroids are included in the World Anti-Doping Agency (WADA) prohibited list as non-threshold analytes. Nevertheless, at least semi-quantitative approaches are necessary before reporting an adverse analytical finding for this class of substances. The liquid chromatography coupled to mass spectrometry (LC-MS) has been used with excellent selectivity and specificity in xenobiotic analysis in complex matrices. Real samples containing exogenous glucocorticosteroids from different administration routes were analyzed using the method proposed. Samples from systemic administration (oral route) presented levels of prednisolone or prednisone higher than $30 \mathrm{ng} \mathrm{mL}^{-1}$, the minimum requirement performance level used as diagnostic parameter. On the other hand, non-systemic routes seem to not have bioavailability to generate an adverse case in doping control analysis. Considering the low number of similar studies available in the literature, more urinary studies could be done using the method reported aiming to provide more information about the excretion profile of glucocorticosteroids administered by systemic and non-systemic routes.

Keywords: glucocorticosteroids, doping control, liquid chromatography, tandem mass spectrometry

\section{Introduction}

Annually, the World Anti-Doping Agency divulges a list of prohibited substances concerning the use of forbidden drugs and methods which constitute a violation of the antidoping code, aiming to guide athletes, doping authorities, trainers and anti-doping laboratories. ${ }^{1}$

Glucocorticosteroids are included in the WADA list due to the potential abuse by athletes, especially motivated by the anti-inflammatory and pain relief actions. In addition,

*e-mail: henriquemarcelo@iq.ufrj.br glucocorticosteroids may affect the nervous system resulting in euphoria and improving the ability of athletes to focus in endurance and/or power events. ${ }^{2,3}$ The prohibition of glucocorticosteroids in sports is related to the route of administration. Glucocorticosteroids are prohibited when administered by oral, intravenous, intramuscular or rectal routes, considering the high bioavailability and potential adverse effects. Topical preparations, when used for auricular, dermatological, gingival, nasal, ophthalmic and perianal disorders are not prohibited. A special declaration (therapeutic use exemption, TUE) shall be requested by the athlete when a glucocorticosteroid is administered 
by intraarticular, periarticular, peritendinous, epidural, intradermal and inhalation routes. ${ }^{1,4}$

Glucocorticosteroids are not included in the set of threshold substances. However, considering there are no markers (e.g., specific metabolites) to indicate the route of administration used by the athlete, the concentration of the glucocorticosteroids or metabolites in the urine has been used to support an adverse analytical finding (AAF) for this class of drugs. Nevertheless, WADA recommends to the anti-doping accredited laboratory not to report a finding of glucocorticosteroids below the minimum required performance level (MRPL), in this case, $30 \mathrm{ng} \mathrm{mL}^{-1} .1,5$ This value was arbitrarily stipulated admitting that topical administration shows low bioavailability, resulting in concentrations under this limit in urine. Therefore, after the initial procedures (screening step), if all the qualitative assay criteria would be fulfilled, some kind of quantitative inference becomes necessary to support an AAF from glucocorticosteroids.

Traditionally, the anti-doping laboratories used mainly gas chromatography coupled to mass spectrometry (GC-MS) in the analytical procedures. ${ }^{6-11}$ As a consequence, the detection of the exogenous glucocorticosteroids used to be an analytical challenge since glucocorticosteroids present poor derivatization yields due to the stereo hindrance in the hydroxy group at the position 17 (Figure 1). ${ }^{12}$

The implementation of liquid chromatography-tandem mass spectrometry (LC-MS/MS) overcomes the difficulties concerning the detection of several classes of prohibited compounds, including glucocorticosteroids., ${ }^{3}, 18$ The main LC-MS/MS advantages highlighted in the literature are associated with the elimination of the derivatization step, enhancement in sensitivity, reduction of time analysis and detection of unknown compounds.

LC-MS/MS has been proposed as a screening approach for several classes of doping agents, including diuretics, stimulants, beta-blockers, some anabolic steroids, anti estrogens, beta-adrenergic drugs and glucocorticosteroids. Since WADA considers the glucocorticosteroids in fact as non-threshold analytes, quantitative approaches are not described for glucocorticosteroids in human urine. As there are not enough studies evaluating the value of $30 \mathrm{ng} \mathrm{mL}^{-1}$ as a boundary-marker in the inference of the route of administration, it seems opportune to use a quantitative approach to evaluate this criterion to declare an adverse analytical finding.

The aims of this study are (i) to report a quantitative method for confirmation purposes using LC-MS/MS technique for the main glucocorticosteroids used by athletes; (ii) to validate the proposed method in the light of WADA rules; (iii) to evaluate the method through the analysis of real samples obtained from volunteers who made use of exogenous glucocorticosteroids for clinical purposes, comparing the urinary concentrations obtained with the WADA boundary-marker.

\section{Experimental}

Quality assurance

All analytical and managerial procedures were accredited for the ISO/IEC 17025 standards, by the Brazilian National Institute of Metrology, Quality and Technology $(\text { INMETRO })^{19}$ jointly with WADA international standards for laboratories. ${ }^{20}$

Reagents, chemicals and solutions

The following substances: betamethasone, budesonide, desonide, dexamethasone, fludrocortisone, flumethasone, flunisolide, fluocortolone, fluprednisolone, $6 \alpha$-methylprednisolone, prednisolone, prednisone, triamcinolone and triamcinolone acetonide were obtained from Steraloids (NewPort, USA). The methyltestosterone used as internal standard was purchased from the Australian Government, National Measurement Institute (Pymble, Australia). Terc-butyl methyl ether (TBME), acetonitrile $(\mathrm{ACN})$ and methanol $(\mathrm{MeOH})$ all HPLC (high performance liquid chromatography) grade, formic acid in analytical grade were obtained from Tedia (Fairfield, EUA). Sodium bicarbonate and sodium carbonate in analytical grade were from Merck (Darmstadt, Germany). Ammonium formate was purchased from Spectrum (Gardena, EUA).

Stock solutions were prepared in methanol at a concentration of $1000 \mathrm{ng} \mu \mathrm{L}^{-1}$. These solutions were further diluted to yield appropriate working solutions for the preparation of the calibration standards. The solutions were sealed and frozen at $-20{ }^{\circ} \mathrm{C}$ until use.

\section{Equipment and conditions}

The HPLC system consisted of a ProStar 410 auto sampler with a $100 \mu \mathrm{L}$ sample loop, with an on line degasser and a ProStar 210 pump system, from Varian (Walnut Creek, CA, EUA). An Eclipse XDB4 C18 column $150 \mathrm{~mm} \times 4.6 \mathrm{~mm} \times 5 \mu \mathrm{m}$ (Agilent Technologies, Palo Alto, CA) and a MetaGuard C18, $2.0 \mathrm{~mm}$ Polaris precolumn (from Varian) were used for the chromatographic separations. The column was maintained at a temperature of $40^{\circ} \mathrm{C}$. The mobile phase consisted of water (A, formic acid $0.1 \%$, ammonium formate $5 \mathrm{mmol} \mathrm{L}^{-1}$ ) and $\mathrm{ACN}$ (B, $0.1 \%$ of formic acid). Two different gradients were 
proposed. Gradient 1: flow rate of $0.4 \mathrm{~mL} \mathrm{~min}^{-1}, 60 \% \mathrm{~A}$ holding $6 \mathrm{~min}$, linear to $20 \% \mathrm{~A}$ and holding $4 \mathrm{~min}$, back to $60 \%$ A until a total run time of $11 \mathrm{~min}$; equilibration time of $4 \mathrm{~min}$. Gradient 2: flow rate of $0.4 \mathrm{~mL} \mathrm{~min}^{-1}$, start with $75 \% \mathrm{~A}$ and linear to $35 \% \mathrm{~A}$ in $21 \mathrm{~min}$, followed by a decrease to $10 \% \mathrm{~A}$ in $21 \mathrm{~min}$ and $6 \mathrm{~s}$ and back to $75 \%$ A until total time of $22 \mathrm{~min}$; equilibration time of $3 \mathrm{~min}$.

The LC effluent was pumped to a 1200L MS/MS triple quadrupole analyzer (Varian) equipped with an electrospray interface (ESI). The tune was made in the autotune mode using polypropylene glycol (PPG). The electrospray was set in the positive mode for all compounds. The acquisition method using the multiple reactions monitoring (MRM) strategy (isolation width of 0.7) was built after optimization of the compound collision energies (CE) for each analyte (Table 1). The fragmentations were done by collision with argon in 2 mbar in the quadrupole 2 (collision induced dissociation). The ESI voltage was set to $5400 \mathrm{~V}$. The capillary temperature was $50{ }^{\circ} \mathrm{C}$. Nebulization gas $\left(\mathrm{N}_{2}\right)$ was used at 36 psi. Drying gas $\left(\mathrm{N}_{2}\right)$ was set at 40 psi and $300{ }^{\circ} \mathrm{C}$. The scan width was maintained at $0.01 \mathrm{Da}$.

Ion suppression

Urines used as negative quality control in routine doping control work were used to estimate the ion suppression of the signal due to matrix interference. These urines were previously extracted and then spiked at $30 \mathrm{ng} \mathrm{mL}^{-1}$ with each glucocorticosteroids in evaluation. This way, it was possible to detect losses in the extraction step. The ion suppression was estimated comparing the response (analyte/internal standard) obtained from these samples, with the equivalent response obtained from the injection of standards (without matrix) at the same final concentration. The residue from sample preparation was reconstituted in $200 \mu \mathrm{L}$ of mobile phase.

\section{Sample preparation}

Internal standard solution $(30 \mu \mathrm{L}$ methyltestosterone, $3 \mathrm{ng} \mu \mathrm{L}^{-1}$ ) was added to $3 \mathrm{~mL}$ urine, followed by addition of $200 \mathrm{mg}$ of carbonate/bicarbonate (1:3, pH 9.0) and then vortexed for $5 \mathrm{~s}$. The extraction was performed with $5 \mathrm{~mL}$ of TBME using an orbital shaker by $20 \mathrm{~min}$. After centrifugation (10 min at $3000 \mathrm{rpm}$ ), the organic layer was transferred to another glass tube and evaporated to dryness using $\mathrm{N}_{2}$ flow and heat $\left(40{ }^{\circ} \mathrm{C}\right)$. The remaining residue was dissolved in $200 \mu \mathrm{L}$ of $\mathrm{ACN}: \mathrm{H}_{2} \mathrm{O}(1: 1 ; 0.2 \%$ of formic acid, $5 \mathrm{mmol} \mathrm{L}{ }^{-1}$ of ammonium formate) and $20 \mu \mathrm{L}$ were injected into the LC-MS/MS system.

\section{Validation of the analytical procedure}

The method was validated for 14 exogenous glucocorticosteroids in the light of the WADA international standards for laboratories (ISL) ${ }^{20}$ following the criteria established for threshold substances, including specificity, intermediate precision, robustness, carryover, limit of quantification, matrix interferences and linearity. In addition, the limit of detection and recovery were determined, despite not explicitly suggested in the WADA ISL. All procedures were developed in the ISO 17025 environment.

\section{Samples from volunteers}

Three volunteers (two women and one man) from 20 to 37 years old were involved in the studies. They were selected observing the eminence administration of glucocorticosteroids under medical prescription. A sample was collected for each volunteer a day before the beginning of the administration. The sample collection was lead observing intervals from 1 to $5 \mathrm{~h}$. A female (volunteer 1) used orally Prelone ${ }^{\circledR}$ (prednisolone $20 \mathrm{mg} \mathrm{g}^{-1}$ ) 1 pill, 12/12 h for 5 days (systemic administration). The second female

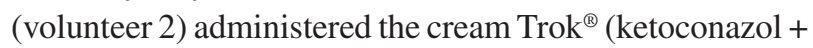
betamethasone dipropionate, $20+0.5 \mathrm{mg} \mathrm{g}^{-1}$ ) once a day for seven days in gynecological area (topical administration). The man (volunteer 3) used a thin layer of Omcilon ${ }^{\circledR}$-A Orabase (triamcinolone acetonide $1 \mathrm{mg} \mathrm{g}^{-1}$ ) in a single dose. The topical medicines were applied following according the prescription. The study using samples from volunteers was supported by the ethical committee of the University Hospital Clementino Fraga Filho, under the protocol number 168/02.

\section{Results and Discussion}

\section{Method development}

\section{Mass spectrometry}

The glucocorticosteroid targets of the study contain keto $\alpha, \beta$-unsaturated and hydroxy groups which could be protonated (Figure 1). As consequence, abundant protonated molecular ions $[\mathrm{M}+\mathrm{H}]^{+}$were observed for all compounds using the ESI interface. Deprotonated molecular ions do not present high abundance in the experimental conditions, so the negative ionization mode was not adopted. ESI parameters such as needle voltage, capillary voltage, nebulization gas pressure and dry gas pressure, and temperature were evaluated for betamethasone aiming to reach out the most intense 
signal as possible for the precursor ion. The same conditions were used for the fragmentation study of all other analytes. In the fragmentation study, all protonated molecular ions showed loss of water in the collision cell. This observation is consistent with the structure of the analytes since all of them present at least two hydroxy groups. A priori, such nonspecific transitions were avoided in the acquisition method. However, for some analytes, as $6 \alpha$-methylprednisolone and desonide, it was included due to the low abundance of the alternative ones. The

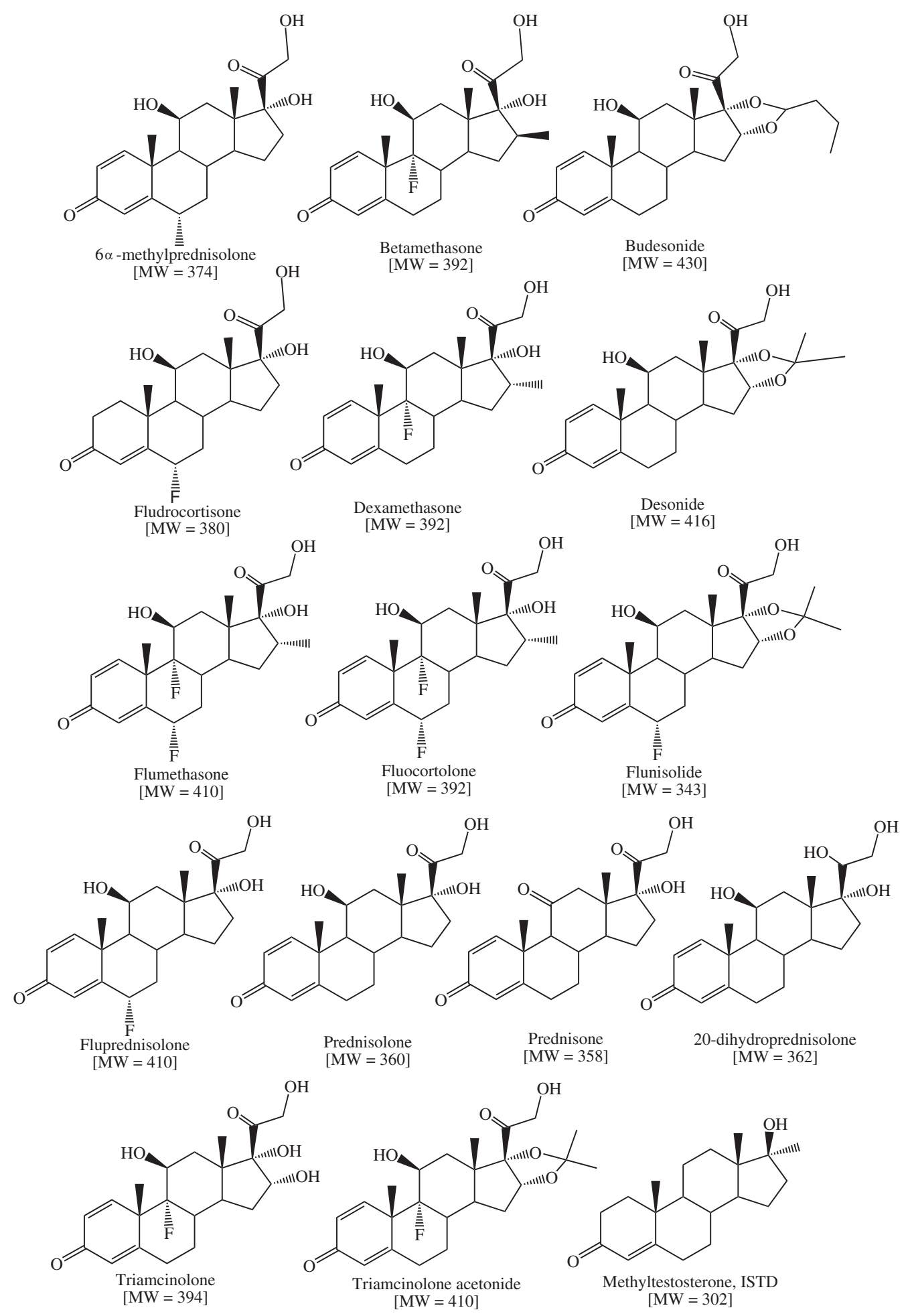

Figure 1. Structures and molecular weights (MW) of synthetic glucocorticosteroids. The hydroxy group at the carbon 17 is characteristic for this class of drugs. The 20-dihydroprednisolone is the metabolite of prednisolone. ISTD: internal standard. 


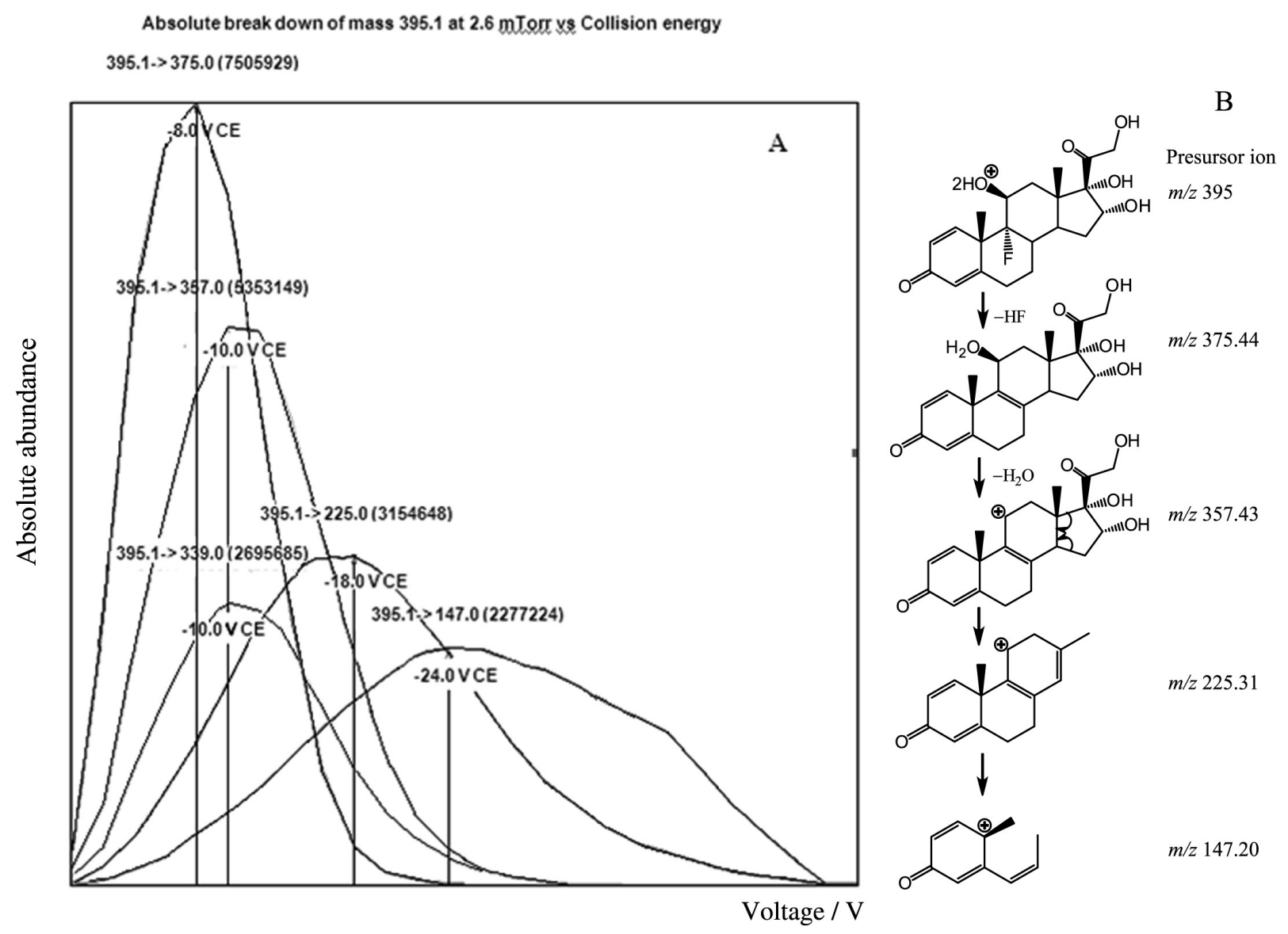

Figure 2. Optimization step in ESI. (A) Fragmentation curve for triamcinolone obtained using collision induced dissociation at $2.6 \mathrm{~m}$ Torr. Ion $\mathrm{m} / \mathrm{z} 395$ was selected as precursor ion. Numbers in parentheses represent the absolute abundance of the product ion obtained during the optimization process. (B) Proposal of the fragmentation mechanism for the diagnostic ions for triamcinolone. Ions $\mathrm{m} / \mathrm{z} 375, \mathrm{~m} / \mathrm{z} 357$ and $\mathrm{m} / \mathrm{z}$. 225 were selected as diagnostic ones in the MRM method (see Table 1).

MRM (multiple reaction monitoring) acquisition method was built through the choice of the product ions formed after the infusion of standards in the triple quadrupole mass spectrometer. Figure 2 presents the result of this optimization for the glucocorticosteroid triamcinolone. The most abundant ions were chosen for acquisition. The final mass spectrometric conditions, precursor ion and product ion from each analyte are presented in Table 1. For qualitative purposes, three ions were acquired for each analyte..$^{21,22}$

\section{Chromatography}

Figure 3 presents the MRM ion chromatogram obtained from a pooled standard solution containing the 14 analytical targets, following the chromatographic conditions described as gradient 1 (total run time of $11 \mathrm{~min}$ ). As expected in reverse phase liquid chromatography, the more polar analytes elute first and methyltestosterone (ISTD), considerably less polar due to the lack of the hydroxy-keto group in $\mathrm{C} 17$, elutes in the end of the chromatogram. Despite of the poor chromatographic resolution, the MRM acquisition mode provides high specificity to distinguish the target analytes present in the sample (see specificity in the validation results). Nevertheless, in the case of isomers, this is not true. Hence, a second gradient (gradient 2) is needed to chromatographically resolve the epimers betamethasone/dexamethasone and the position isomers flunisolide/triamcinolone acetonide (Figure 1).

Figure 4 presents the chromatogram obtained for the epimers betamethasone/dexamethasone in gradient 2 (total run time of $22 \mathrm{~min}$ ). In this slower run, the chromatographic resolution reached is still below 1.5 (base-line resolution). However, it is enough for qualitative purposes, allowing the use of relative retention time (retention time of the analyte/ retention time of the internal standard) or co-injection for unequivocal identification. The retention times obtained from the two pairs of isomers are given in Table 2. The differentiation between dexamethasone and betamethasone was previously discussed by Deventer and Delbeke. ${ }^{3}$ The discrimination between these isomers based in the relative abundances from specific product ions obtained after a MS (mass spectrometry $)^{3}$ experiment was demonstrated using the $m / z, 361$ as intermediated ion. In the work, the authors 
Table 1. Precursor ion, product ion, collision energy and retention time for each exogenous glucocorticosteroid

\begin{tabular}{llll}
\hline & Analyte & Precursor ion $(\mathrm{m} / \mathrm{z}) \rightarrow$ Product ion $(\mathrm{m} / \mathrm{z})$ and $($ Collision energy / eV) & $\mathrm{t}_{\mathrm{R}} / \mathrm{min} *$ \\
$\mathbf{1}$ & triamcinolone & $395 \rightarrow 375(-4 \mathrm{~V}), 395 \rightarrow 357(-6 \mathrm{~V}), 395 \rightarrow 225(-10 \mathrm{~V})$ & 4.7 \\
$\mathbf{2}$ & fluprednisolone & $379 \rightarrow 171(-20 \mathrm{~V}), 379 \rightarrow 341(-6 \mathrm{~V}), 379 \rightarrow 323(-8 \mathrm{~V})$ & 5.6 \\
$\mathbf{3}$ & prednisolone & $361 \rightarrow 343(-6 \mathrm{~V}), 361 \rightarrow 307(-6 \mathrm{~V}), 361 \rightarrow 325(-6 \mathrm{~V})$ & 5.8 \\
$\mathbf{4}$ & prednisone & $359 \rightarrow 313(-6 \mathrm{~V}), 359 \rightarrow 341(-6 \mathrm{~V}), 359 \rightarrow 323(-8 \mathrm{~V})$ & 5.8 \\
$\mathbf{5}$ & fludrocortisone & $381 \rightarrow 181(-30 \mathrm{~V}), 381 \rightarrow 183(-34 \mathrm{~V}), 381 \rightarrow 211(-28 \mathrm{~V})$ & 5.9 \\
$\mathbf{6}$ & 6o-methylprednisolone & $375 \rightarrow 357(-6 \mathrm{~V}), 375 \rightarrow 339(-6 \mathrm{~V}), 375 \rightarrow 321(-8 \mathrm{~V})$ & 6.5 \\
$\mathbf{7}$ & flumethasone & $411 \rightarrow 253(-6 \mathrm{~V}), 411 \rightarrow 121(-26 \mathrm{~V}), 411 \rightarrow 391(-6 \mathrm{~V})$ & 6.5 \\
$\mathbf{8}$ & betamethasone / dexamethasone**a & $393 \rightarrow 373(-8 \mathrm{~V}), 393 \rightarrow 355(-10 \mathrm{~V}), 393 \rightarrow 147(-24 \mathrm{~V})$ & 6.6 \\
$\mathbf{9}$ & flunisolide**b & $435 \rightarrow 321(-10 \mathrm{~V}), 435 \rightarrow 339(-10 \mathrm{~V}), 435 \rightarrow 223(-18 \mathrm{~V})$ & 7.5 \\
$\mathbf{1 0}$ & triamcinolone acetonide**b & $435 \rightarrow 415(-4 \mathrm{~V}), 435 \rightarrow 397(-8 \mathrm{~V}), 435 \rightarrow 213(-18 \mathrm{~V})$ & 7.5 \\
$\mathbf{1 1}$ & fluocortolone & $377 \rightarrow 303(-10 \mathrm{~V}), 377 \rightarrow 171(-16 \mathrm{~V}), 377 \rightarrow 321(-8 \mathrm{~V})$ & 7.6 \\
$\mathbf{1 2}$ & desonide & $417 \rightarrow 323(-8 \mathrm{~V}), 417 \rightarrow 399(-8 \mathrm{~V}), 417 \rightarrow 341(-8 \mathrm{~V})$ & 8.2 \\
$\mathbf{1 3}$ & budesolide & $431 \rightarrow 413(-6 \mathrm{~V}), 431 \rightarrow 323(-8 \mathrm{~V}), 431 \rightarrow 147(-20 \mathrm{~V})$ & 10.2 \\
$\mathbf{1 4}$ & methyltestosterone & $303 \rightarrow 97(-20 \mathrm{~V}), 303 \rightarrow 109(-20 \mathrm{~V}), 303 \rightarrow 285(-10 \mathrm{~V})$ & 10.9 \\
\hline
\end{tabular}

*Retention time obtained through gradient 1: flow rate of $0.4 \mathrm{~mL} \mathrm{~min}^{-1}, 60 \%$ A holding 6 min, linear to $20 \% \mathrm{~A}$ and holding 4 min, back to $60 \% \mathrm{~A}$ until a total run time of $11 \mathrm{~min}$; equilibration time of $4 \mathrm{~min}$; **a,b when separation of these isomers becomes necessary, it could the achieved by gradient 2: flow rate of $0.4 \mathrm{~mL} \mathrm{~min}^{-1}$, start with $75 \% \mathrm{~A}$ and linear to $35 \% \mathrm{~A}$ in $21 \mathrm{~min}$, followed by a decrease to $10 \% \mathrm{~A}$ in $21 \mathrm{~min}$ and $6 \mathrm{~s}$, and back to $75 \% \mathrm{~A}$ until total time of $22 \mathrm{~min}$; equilibration time of $3 \mathrm{~min}$.

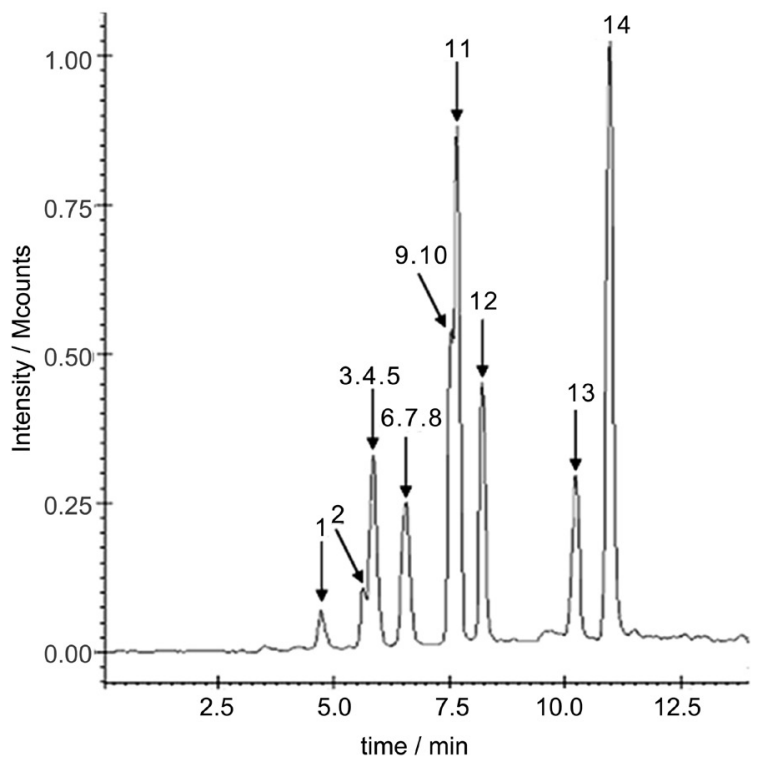

Figure 3. MRM ion chromatogram obtained using the gradient 1 procedure. An urine spiked with a pooled standard solution containing 14 exogenous glucocorticosteroids was used. Gradient 1: flow rate of

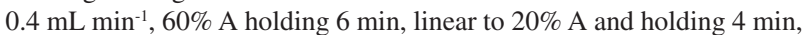
back to $60 \% \mathrm{~A}$ until a total run time of $11 \mathrm{~min}$; equilibration time of $4 \mathrm{~min}$. For the MRM acquisition method see Table 1 .

reported that for betamethasone, the ion $\mathrm{m} / \mathrm{z} 307$ is the most abundant. On the other hand, for dexamethasone, the ion $\mathrm{m} / \mathrm{z}, 345$ is the most intense.

However, this kind of experiment is not feasible in a triple quadrupole analyzer.

As highlighted by Pozo et al.,${ }^{15}$ the ion suppression from the analytical signal related to the matrix components is one of the most important sources of errors in LC-MS/MS, especially in quantitative methods. This could be particularly critical in a complex matrix such as urine. Since the use of labeled internal standard for each analyte is not possible in comprehensive methods as the present one, the evaluation of the ion suppression becomes essential. The compromise between the signal intensity of each analyte and the dilution of the sample was the parameter observed in this analysis. In thesis, the ion suppression is more important when more matrix components are present. As a result, LC-MS/MS methods were developed adopting low sample volumes. Obviously, it is necessary to consider the impact in the sensitivity. Hence, the signals of the analytes obtained in the LC-MS/MS system when using 1, 2 and $3 \mathrm{~mL}$ of urine were evaluated. Indeed, in the experimental conditions presented, it was observed a considerable range of response factors (signal from the analyte/mass injected) among the glucocorticosteroids. The compromise with the global sensitivity of the method was considered, and the sample volume of $3 \mathrm{~mL}$ was adopted. A limit of quantification (LOQ) of, at least, $15 \mathrm{ng} \mathrm{mL}^{-1}$ (1/2 MRPL) was reached for each analyte. The signals obtained spiking the glucocorticosteroids at $30 \mathrm{ng} \mathrm{mL}^{-1}$ after the extraction step were compared with the same data when the standards without matrix were injected. The experiment was performed in triplicate and the $t$-test was used to evaluate the results. No ion suppression could be observed. Nevertheless, it is important to keep in mind that, in the extreme cases, the ion suppression can be strongly different between sample to sample. In athletes, the use of painkillers (allowed) and non-steroidal anti-inflammatory drugs can be very common. If for any reason, there will be 


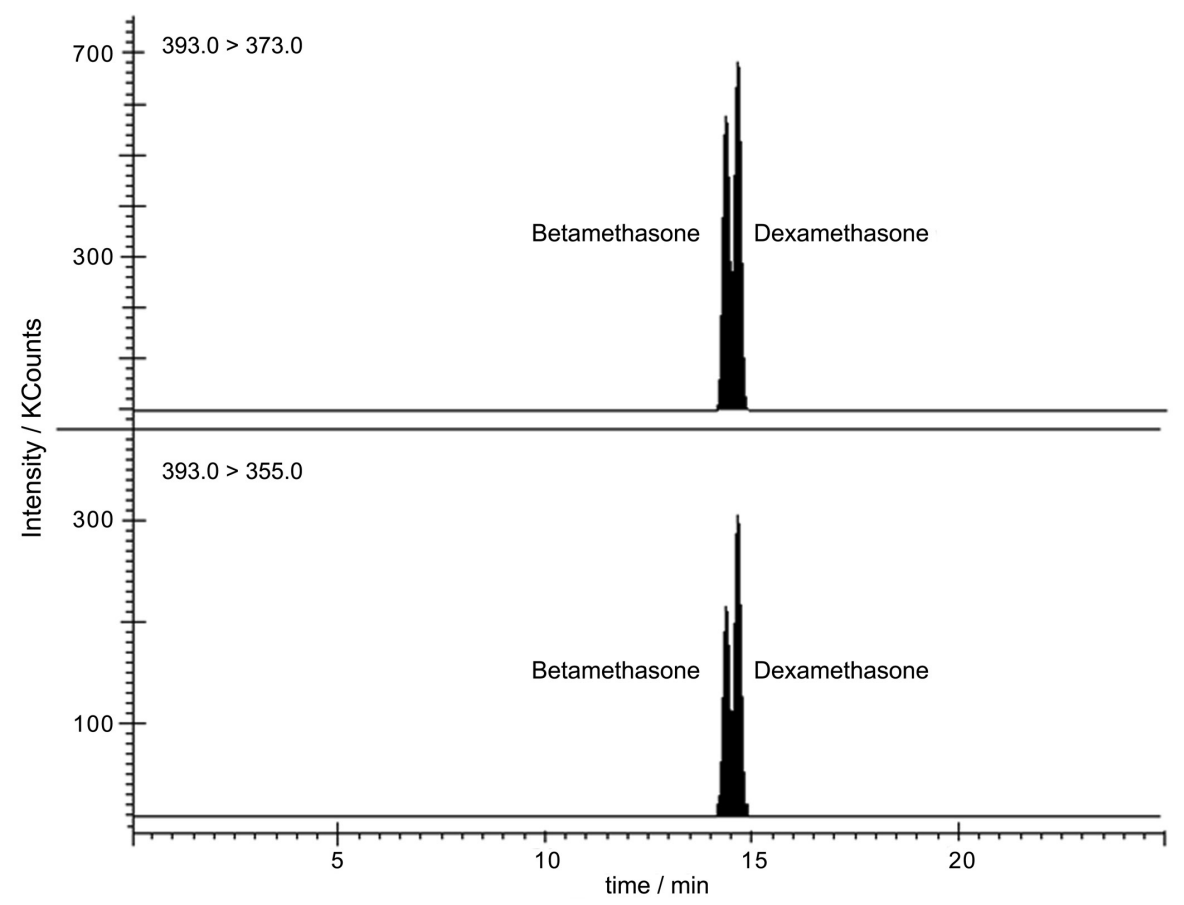

Figure 4. Ion chromatograms from a urine spiked with betamethasone and dexamethasone at $30 \mathrm{ng} \mathrm{mL}^{-1}$ obtained using the gradient 2: flow rate of $0.4 \mathrm{~mL} \mathrm{~min}{ }^{-1}$, start with $75 \% \mathrm{~A}$ and linear to $35 \% \mathrm{~A}$ in $21 \mathrm{~min}$, followed by a decrease to $10 \% \mathrm{~A}$ in $21 \mathrm{~min}$ and $6 \mathrm{~s}$, and back to $75 \% \mathrm{~A}$ until total time of $22 \mathrm{~min}$; equilibration time of $3 \mathrm{~min}$.

Table 2. Retention times obtained for the isomeric pairs in gradient 2: flow rate of $0.4 \mathrm{~mL} \mathrm{~min}^{-1}$, start with $75 \% \mathrm{~A}$ and linear to $35 \% \mathrm{~A}$ in $21 \mathrm{~min}$, followed by a decrease to $10 \% \mathrm{~A}$ in $21 \mathrm{~min}$ and $6 \mathrm{~s}$, and back to $75 \% \mathrm{~A}$ until total time of $22 \mathrm{~min}$; equilibration time of $3 \mathrm{~min}$

\begin{tabular}{lc}
\hline Analyte & $\mathrm{t}_{\mathrm{R}} / \min$ \\
\hline Betamethasone & 14.27 \\
Dexamethasone & 14.52 \\
Flunisolode & 18.05 \\
Triamcinolone acetonide & 18.33 \\
\hline
\end{tabular}

a suspicion of ion suppression (e.g., information obtained from screening step reports the presence of an allowed drug in extremely high concentration), a different sample preparation condition could be necessary to confirm the quantitative data. For more accurate results, labeled internal standards are recommended.

\section{Validation results}

The method was validated in the light of the international standards for laboratories from WADA ${ }^{20}$ for all analytes. To evaluate the linearity, calibration curves were built around the concentration of $30 \mathrm{ng} \mathrm{mL}^{-1}$. Using the concentration levels $15,30,45,60$ and $75 \mathrm{ng} \mathrm{mL}^{-1}$, all curves followed a homoscedastic model according to the Cochran test. Hence, using a least squares fit, good linearity $\left(r^{2} \geq 0.99\right)$ was observed for all substances. None of the calibration curves was forced through the origin axes. The intermediate precision was assessed comparing the values of the repeatability in three different days. The $t$-test was used to compare the averages and the ANOVA test was used to compare the variances obtained. All results were considered equivalent and no intra-assay imprecision was higher than $20 \%$. In the robustness evaluation, no differences were observed in the results after intentional alterations in some key points (e.g., extraction time and temperature of evaporation) of the method. Consecutive injections of positive controls (spiked with the exogenous glucocorticosteroids) and negative controls demonstrated the absence of carryover. All analytes presented recoveries above $90 \%$, with exception of triamcinolone $(71 \%)$. All analytes presented limit of detection below $6 \mathrm{ng} \mathrm{mL}^{-1}$. This parameter was estimated considering the MRM channel with the lowest signal to noise ratio, therefore fulfilling the WADA criteria for identification. The limit of quantification was established as the first point of the calibration curve of the linearity study $\left(15 \mathrm{ng} \mathrm{mL}^{-1}\right)$. All analytes present imprecision smaller than $20 \%$ at this concentration level. The matrix interference was evaluated after the injection of ten negative samples. No signal was observed in any MRM channel for any analyte. According to the WADA ISL, the specificity is the ability of the assay to discriminate between compounds with closely related structures. ${ }^{20}$ Despite of the similarity of the exogenous glucocorticosteroids, the MRM experiment allows excellent specificity as demonstrated for the pair prednisolone/prednisone (Figure 5). The 
experiment was performed by processing and injecting two different samples: (i) urine spiked with prednisolone and (ii) urine spiked with prednisone. The difference between the analytes relies just in the position 11, a keto group for prednisone and a hydroxy group for prednisolone (Figure 1). Even considering the closely related structures, no interference was observed for the transitions in the MRM channels. As described before, in the case of isomers, a second gradient was necessary to reach out specificity.

More detailed data obtained during the validation process are available in Table S1 (in the Supplementary Information (SI) section).

\section{Application for real samples}

\section{Systemic administration}

All samples provided from the excretion studies were analyzed by the proposed method. An excretion profile of prednisolone and metabolites was carried after urine samples from volunteer 1. Figure 6 presents the excretion profile (prednisolone and prednisolone in $\mathrm{ng} \mathrm{mL}^{-1} v s . \mathrm{h}$ ). As expected, with continuing systemic administration, the concentrations of prednisolone observed in several moments are considerably higher than $30 \mathrm{ng} \mathrm{mL}^{-1}$. These concentrations were indeed higher than the last concentration

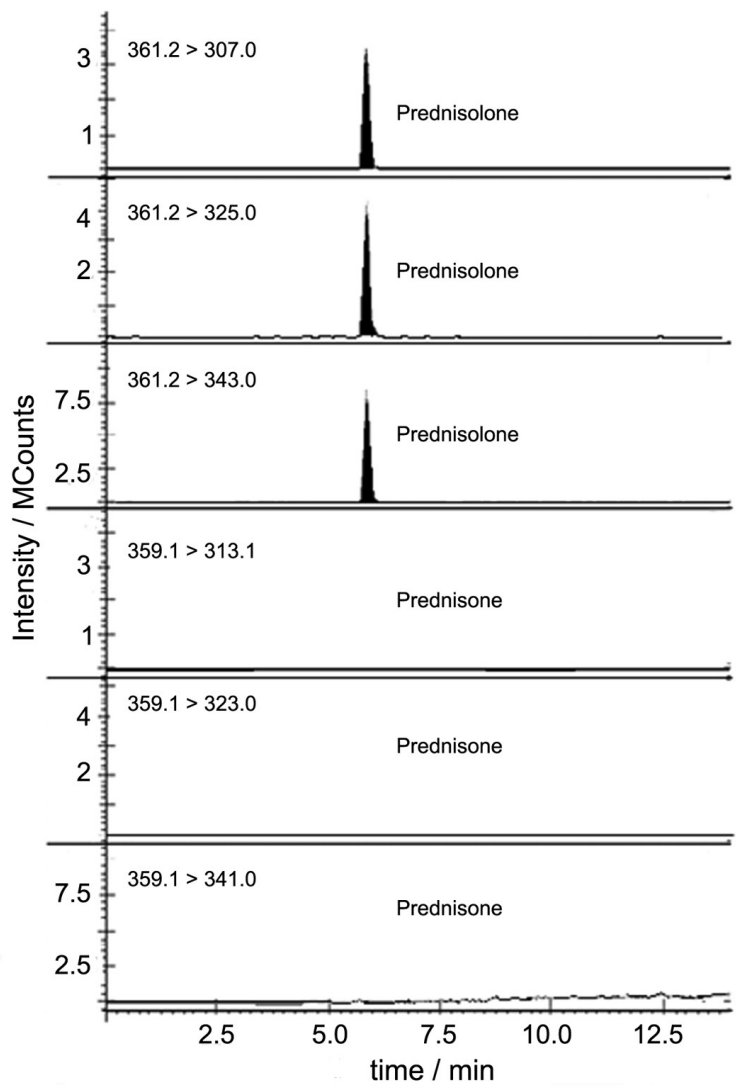

point used in the quantification method. Hence, this concentration values was just estimated. The results from this excretion study should be evaluated in a more comprehensive way considering the formation of metabolites.

The metabolism of prednisolone is one of the best studied among exogenous glucocorticosteroids, being prednisone and 20-dihydroprednisolone the main metabolites described. In Figure 6, it is possible to observe the higher concentration of prednisolone in relation to the metabolite prednisone. Even so, the concentrations of prednisone until $132 \mathrm{~h}$ after the first administration were above MRPL.

Indeed, according the Figure 6B, when the administration of the prednisolone is interrupted $(108 \mathrm{~h}$ after the beginning of the study), the concentration of the prednisolone in urine drops drastically. As a result, prednisone could produce an adverse analytical finding in the sample collected in $\mathrm{t}=132 \mathrm{~h}$, meanwhile the concentration of prednisolone already dropped below $30 \mathrm{ng} \mathrm{mL}^{-1} .35 \mathrm{~h}$ after the last administration, both prednisolone and prednisone are below the limit of decision concentration, resulting in a negative case.

Due to the lack of 20-dihydroprednisolone standard, no quantitative inference could be done for this metabolite during the study. However, according to the data, the 20-dihydroprednisolone presents a detection window greater

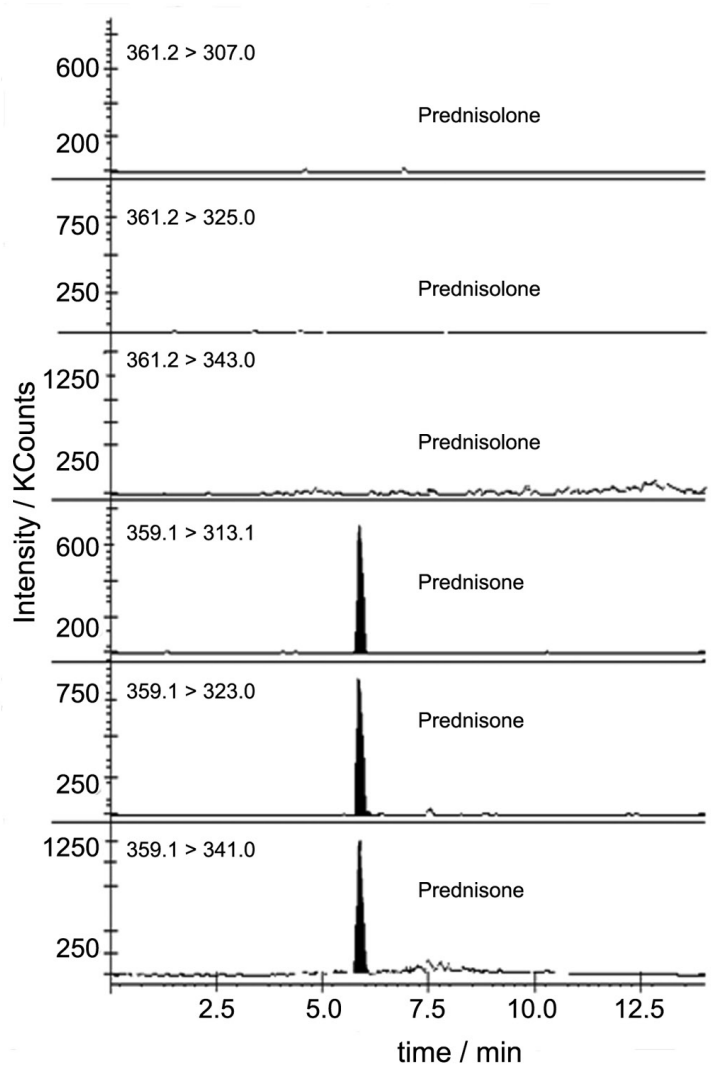

Figure 5. Specificity evaluation. (A) Urine spiked with prednisolone and (B) urine spiked with prednisone. No interference was observed between the injections. 


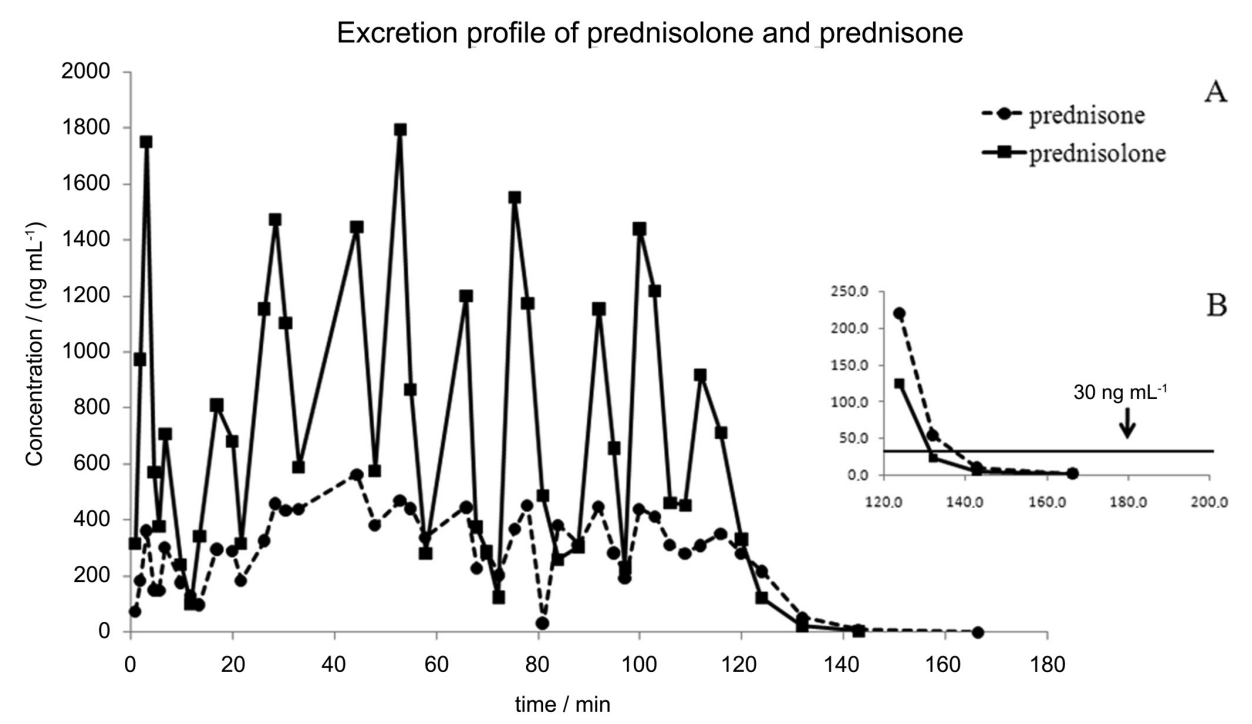

Figure 6. Prednisolone and prednisone urinary excretion profile after oral administration of $20 \mathrm{mg}$ of prednisolone $12 / 12 \mathrm{~h}$, during 5 days.

than prednisone and prednisolone. As a consequence, the use of a reference material of this metabolite to quantitative purposes could be useful, improving the information relative to an adverse analytical finding. Anyway, even the observation of this metabolite in a qualitative scope could corroborate with the interpretation in the analytical finding of prednisolone. Figure S1 (in the SI section) highlights the window of detectability for prednisolone and the main metabolites.

\section{Non-systemic administration}

Considering the two cases of non-systemic administration investigated, no glucocorticosteroids could be detected for all samples analyzed. Figure 8 presents the chromatograms obtained from the analytical batch from the betamethasone study (topical administration in gynecological area). In Figure 7 the positive quality control was spiked with $30 \mathrm{ng} \mathrm{mL}^{-1}$ of betamethasone. No signal was observed as a result of the poor bioavailability of the topic route, even after 7 days of administration. The triamcinolone acetonide excretion study provided similar results (data not shown).

Considering the high sensitivity and specificity of the LC-MS/MS technique and the low concentrations observed for the glucocorticosteroids in urine after nonsystemic administration, the reduction of the MRPL for this class of drugs can be postulated. Nevertheless, more evaluations are needed considering more volunteers, other glucocorticosteroids and different non-systemic routes to support such proposal. This kind of action can potentially reduce the number of false-negative results as a consequence of the sampling of the athlete in the end of the excretion of the glucocorticosteroids administered by a systemic route. Regarding the lack of detection of exogenous glucocorticosteroids after non-systemic

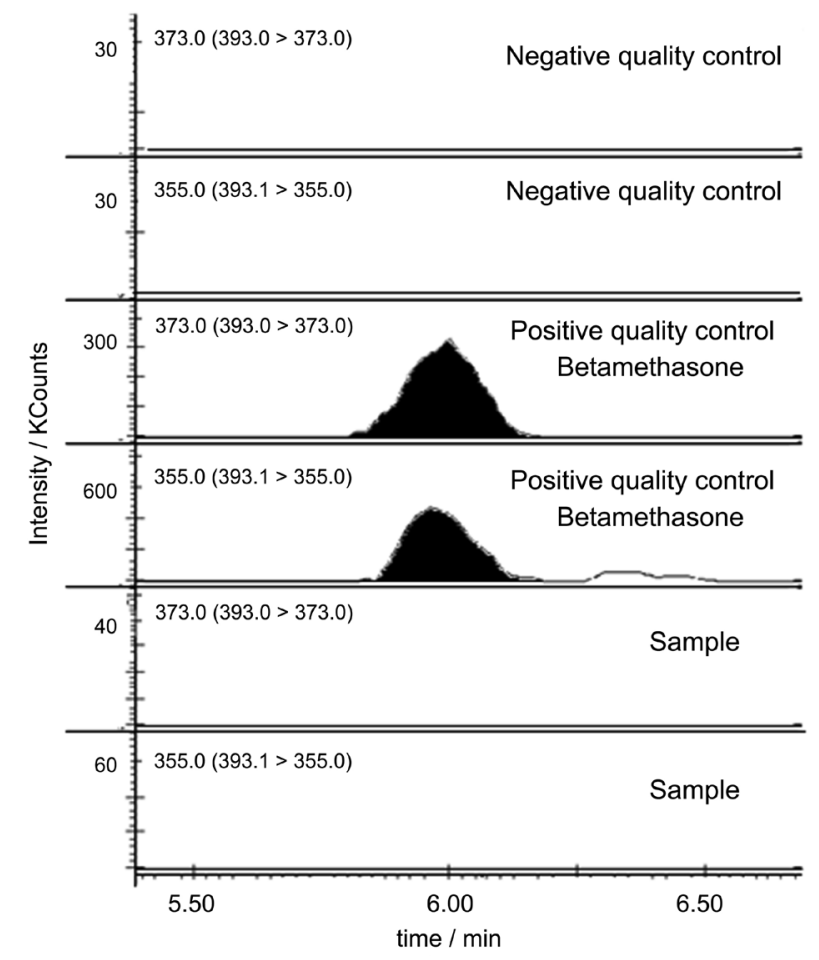

Figure 7. Chromatograms from negative quality control, positive quality control and sample from the excretion study of betamethasone dipropionate. No signal observed after 7 days of topical administration.

administration, it looks quite improbable that an incidental case of AAF would result from a topic administration already described for other classes of substances. ${ }^{23}$

\section{Conclusions}

A simple and sensitive method was developed and validated for quantitative analysis of fourteen 
exogenous glucocorticosteroids using the LC-MS/MS. The method, based on the multiple reactions monitoring acquisition approach, exhibited excellent sensitivity and linearity. Despite of the structural similarity between the glucocorticosteroids studied and the endogenous ones, the method shows excellent specificity and no matrix interference. Aiming to reach the qualitative requirements before the quantitative step, a special chromatography gradient should be used to distinguish the isomers betamethasone/dexamethasone and triamcinolone acetonide/ flunisolide. As expected, glucocorticosteroids systemic administration resulted in huge urinary concentrations, exceeding the WADA boundary-marker of $30 \mathrm{ng} \mathrm{mL}^{-1}$. On the other hand, no glucocorticosteroids or metabolites were observed from non-systemic administrations. More urinary studies using the method reported could provide additional information about the excretion profile of glucocorticosteroids administered by non-systemic routes. These results could support a suggestion of reduction of the WADA boundary-marker value, lowering the margin of misuse of these substances in sport.

\section{Supplementary Information}

Supplementary information is available free of charge at http://jbcs.sbq.org.br as PDF file.

\section{Acknowledgments}

The authors acknowledge CBF, FAPERJ, CNPq, CAPES and FUJB for financial support.

\section{References}

1. http://www.wada-ama.org/Documents/World_Anti-Doping Program/WADP-Prohibited-list/2012/WADA_Prohibited List_2012_EN.pdf accessed in August 2012.

2. http://www.biocompare.com/Application-Notes/41909Screening-Of-Corticosteroids-In-Urine-By-NegativeAtmospheric-Pressure-Chemical-Ionization-LC-MS-MS/ accessed in August 2012.

3. Deventer, K.; Delbeke, F. T.; Rapid Commun. Mass Spectrom. 2003, 17, 2107.

4. http://www.wada-ama.org/Documents/World_Anti-Doping _ Program/WADP-IS-TUE/2011/WADA_TUE_Guidelines V6.0_EN.pdf accessed in August 2012.

5. http://www.wada-ama.org/Documents/World_Anti-Doping_ Program/WADP-IS-Laboratories/Technical_Documents/ WADA_TD2010MRPLv1.0_Minimum\%20Required\%20 Performance\%20Levels_Sept\%2001\%202010_EN.pdf accessed in August 2012.
6. Schänzer, W.; Delahaut, P.; Geyer, H.; Machnik, M.; Horning, S.; J. Chromatogr., B: Anal. Technol. Biomed. Life Sci. 1996, 687, 93.

7. Marques M. A. S.; Pereira, H. M. G.; Aquino Neto, F. R.; J. Braz. Chem. Soc. 2006, 17, 382.

8. Marques, M. A. S.; Pereira, H. M. G.; Padilha, M. C.; Aquino Neto, F. R.; J. Chromatogr. 2007, 1150, 215.

9. Silva, A. I.; Pereira, H. M. G.; Casilli, A.; Conceição, F. C.; Aquino Neto, F. R; J. Chromatogr. 2009, 1216, 2913.

10. Aguilera, R.; Chapman, T. E.; Pereira, H. M. G.; Oliveira, G. C.; Illanes, R. P.; Fernandes, T. F.; Azevedo, D. A.; Aquino Neto, F. R.; J. Steroid Biochem. Mol. Biol. 2009, 115, 107.

11. Marques, M. A. S.; Damasceno, L. M. P.; Pereira, H. M. G.; Caldeira, C. M.; Dias, B. F. P.; Vargens; D. G.; Amoedo, N. D.; Volkweis, R. O.; Volkweis, R. O. V.; Rumjanek, F. D.; Aquino Neto, F. R.; J. Forensic Sci. 2005, 50, 587.

12. Pereira, H. M. G.; Marques, M. A. S.; Cardoso, J. N.; Aquino Neto, F. R.; Quim. Nova 2002, 25, 1096.

13. Thevis, M.; Geyer, H.; Mareck, U.; Schänzer, W.; J. Mass Spectrom. 2005, 40, 955.

14. Mazzarino, M.; Botrè, F.; Rapid Commun. Mass Spectrom.2006, $20,3465$.

15. Pozo, O. J.; Van Eenoo, P.; Deventer, K.; Delbeke, F. T.; Anal. Bioanal. Chem. 2007, 389, 1209.

16. Mazzarino, M.; de la Torre, X.; Botrè, F.; Anal. Bioanal. Chem. 2008, 392, 681.

17. Pereira, H. M. G.; Padilha, M. C.; Bento, R. M. A.; Cunha, T. P.; Lascas, N. A. G.; Aquino Neto, F. R.; TrAC, Trends Anal. Chem. 2008, 27, 648.

18. Pereira, H. M. G.; Padilha, M. C.; Aquino Neto, F. R.; Bioanalysis 2009, 1, 1475.

19. http://www.inmetro.gov.br/credenciamento/acre_lab.asp accessed in August 2012.

20. http://www.wada-ama.org/Documents/World_Anti-Doping Program/WADP-IS-Laboratories/ISL/WADA_Int_Standard_ Laboratories_2012_EN.pdf accessed in August 2012.

21. http://www.wada-ama.org/Documents/World_Anti-Doping_ Program/WADP-IS-Laboratories/Technical_Documents/ WADA_TD2010IDCRv1.0_Identification\%20Criteria\%20 for\%20Qualitative\%20Assays_May\%2008\%202010_EN.doc. pdf accessed in August 2012.

22. Sardela, V. F.; Motta, M. T. R.; Padilha, M. C.; Pereira, H. M. G.; Aquino Neto, F. R.; J. Chromatogr., B: Anal. Technol. Biomed. Life Sci. 2009, 877, 3003.

23. Pereira, H. M. G.; Marques, M. A. S.; Talhas, I. B.; Aquino Neto, F. R.; Clin. Chem. 2004, 50, 456.

Submitted: April 20, 2011

Published online: December 7, 2012 